\title{
EVALUATION OF GRAPE SEED EXTRACT (VITIS VINIFERA) AS A CROSSLINKER ON THE STABILITY OF DENTINE COLLAGEN IN TOTAL-ETCH ADHESIVE SYSTEMS: AN IN VITRO STUDY
}

\author{
D DENNIS, FENIKA MAITARI
}

Department of Conservative Dentistry, Faculty of Dentistry, Center of Excellence, Green Chitosan and Advanced Material, Universitas Sumatera Utara, Indonesia. Email: dennis_dionisius@yahoo.co.uk

Received: 10 February 2019, Revised and Accepted: 30 March 2019

\section{ABSTRACT}

Objective: The bond strength between resin and dentine is determined by the integrity of collagen, dentine, and resin monomers. The susceptibility of the dentine bond results from the instability of the bonding structure that adheres to the bonding material. This can be achieved using collagen crosslinker, synthetically and naturally in dentine substrates which are effective in protecting collagen fibrils from degradation, as proanthrocyanidin. The aim of this study was to see the effect of grape seed extract as a crosslinker on the stability of dentine collagen and see the differences between groups.

Methods: This study used 27 fresh premolars or third molars which were divided into three Groups, namely Group I giving grape seed extract $6.5 \%$, Group II giving chlorhexidine $2 \%$, and Group III only giving bonding ingredients. Samples were analyzed using scanning electron microscopy with $\times 1000$ magnification.

Results: Data were analyzed using kappa statistic, Kruskal-Wallis, and Mann-Whitney. The result of the study significant differences between treatment groups $(\mathrm{p}<0.05)$ and the $2 \%$ chlorhexidine group showed the highest value compared to the grape seed extract group and without treatment.

Conclusion: Grape seed extract can be used as an alternative to chlorhexidine as a crosslinker to maintain bone strength of the composite restoration.

Keywords: Bond strength, Proanthocyanidine, Grape seed extract, Crosslinker

(C) 2019 The Authors. Published by Innovare Academic Sciences Pvt Ltd. This is an open access article under the CC BY license (http://creativecommons. org/licenses/by/4. 0/) DOI: http://dx.doi.org/10.22159/ajpcr.2019.v12i5.32506

\section{INTRODUCTION}

The use of composite resins for dental restorations in the past decade to restore carious teeth has greatly increased. The need for esthetics and low toxicity makes popular composite resins. The initial problem in using composite resins is low durability due to the use and loss of anatomical shape after use [1]. Composite resins contain bonds that are not stable, so they are easily degraded by acid or low pH. Acid causes polymer degradation and filler components which can affect the hardness and roughness of the composite resin surface [2].

Various studies have shown that there is a decrease in composite resin bonds in dentine which in this case can be attributed to the complexity of dentine structures such as increasing tubular numbers and diameter with intertubular dentine matrix which is much less than superficial dentine [3]. Successful adhesion to enamel with a strong adhesive value height cannot be achieved equivalent to dentine. Dentine has a higher water and organic content than enamel, which causes dentine to be moist, so that the adhesion system must be hydrophilic [4]

Dentine has a composition of $70 \%$ minerals (apatite crystals), $18 \%$ is in the form of organic components, namely collagen type 1 and noncollagen proteins, while $12 \%$ is water [4]. Dentin collagen is needed to form a cross bond that can provide strength and stabilization, so it is needed as a biomaterial [5].

Infiltration of resin monomers into dentinal tubulartissue and intertubulewill form micromechanical retention areas called hybrid layers. Micromechanical retention between resin and dentin is the main mechanism of resin-dentine bond. The bond strength between resin and dentine is determined by the integrity of collagen, dentine, and resin monomers [6,7].

The resistance of the hybrid layer depends on the stability of each component, such as collagen fibrils and polymer chains. However, collagen fibrils which are not fully infiltrated by resin monomers when exposed to acid etching inhibit optimal protection against denaturation. Unprotected collagen is more susceptible to creep and cyclic fatigue ruptures after functioning for a long time. In the fibril collagen, resins are filled and surrounded by water, which participates in the matrix hydrolysis of resin by esterases and collagen by collagenolytic enzymes [8]

The susceptibility of the dentine bond results from the instability of the bonding structure that adheres to the bonding material. This is due to physical and chemical factors including hydrolysis and enzymatic degradation by matrix metalloproteinases (MMPs) which can increase the risk of degradation of collagen dentine in hybrid layers. [8,9] In the degradation of hybrid layers by MMPs, MMPs inhibitors act to protect collagen in the hybrid layer. Chlorhexidine 2\% can inhibit MMP-2, -8, and -9 and, even at low concentrations, can maintain the integrity of the hybrid layer. The role of chlorhexidine is to delay dentine demineralization but does not stop the degradation of the bonds permanently. However, chlorhexidine also has deficiencies in the form of discoloration and bitter taste $[10,11]$.

Mechanical properties of collagen and its resistance to enzymatic degradation can be improved by increasing the formation of intraand inter-molecular and intermicrofibrillar cross-links. This can be achieved using synthetic and natural collagen cross-linker in the dentine substrate before bonding procedures [12].

The use of collagen cross-linking agent is proposed to improve the mechanical properties of the dentine matrix, reduce the level of biodegradation of collagen, increase the nature of dentine resin bonding, and extend the life of adhesive restoration [5]. One natural collagen cross-linker is proanthocyanidin. Proanthocyanidin, called condensed tannins, is a structure of flavan-3-ol [13]. Proanthocyanidin is found in fruits, vegetables, nuts, seeds, and flowers [14].

Grape seed compounds include flavonoids, polyphenols, anthocyanins, proanthocyanidins, procyanidins, and the stilbene 
derivative resveratrol $[15,16]$. Grape seed extract has been reported to have a broad spectrum of pharmacological and therapeutic effects such as antioxidative, anti-inflammatory, and antimicrobial activities, as well as cardioprotective, hepatoprotective, and neuroprotective potentials [15].

There has been a lot of research testing about proanthocyanidin in increasing shear bond strength and tensile bond strength, but examining the part of dentin collagen directly does not yet exist, so researchers are interested in knowing the effects of proanthocyanidin on grape seed extract on the stability of dentine collagen.

\section{MATERIALS AND METHODS}

Sample

This type of research is experimental in vitro laboratory using posttest group design with control group. The study sample consisted of 27 premolars and third molars.

\section{Methods}

About $50 \mathrm{~g}$ of fresh grape seeds are used to make grape seed extract with an additional $70 \%$ ethanol. Teeth that have been removed are then planted in a cast. Perform the occlusal preparation so that it is dentate. Grape seed extract was applied for the first group and chlorhexidine was applied for second group, and the third group was only using bonding agent without pre-treatment. After that, the teeth were cut into two parts vertically, the roots were removed and the only remaining parts were dentin and composite resin

Samples were analyzed using scanning electron microscopy with 1000 magnification. After that, the results obtained were tested with Kruskal-Wallis

\section{RESULTS}

From the results of Table 1, it shows that there is an effect of extract of grape seeds as a crosslinker on the stability of dentine collagen. It is known that there are significant differences between the treatment groups $(\mathrm{p}<0.05)$. In Chart 1 , group which applied chlorhexidine $2 \%$ showed the highest value compared to the grape seed extract group and without treatment.

\section{DISCUSSION}

Biomodification of the demineralization of the collagen matrix with crosslinking agents plays an important role in increasing dentin biomechanics. Strengthening collagen fibrils by crosslinker agents can

Table 1: Result of Kruskal-Wallis test

\begin{tabular}{lllll}
\hline Group & $\mathbf{n}$ & $\mathbf{X} \pm$ SD & Median & $\mathbf{p}$ \\
\hline Grape seed & 9 & $1.11 \pm 0.601$ & 1 & 0.002 \\
CHX & 9 & $1.89 \pm 0.782$ & 2 & \\
Negative control & 9 & $0.44 \pm 0.864$ & 0 & \\
\hline
\end{tabular}

CHX: Chlorhexidine, SD: Standard deviation

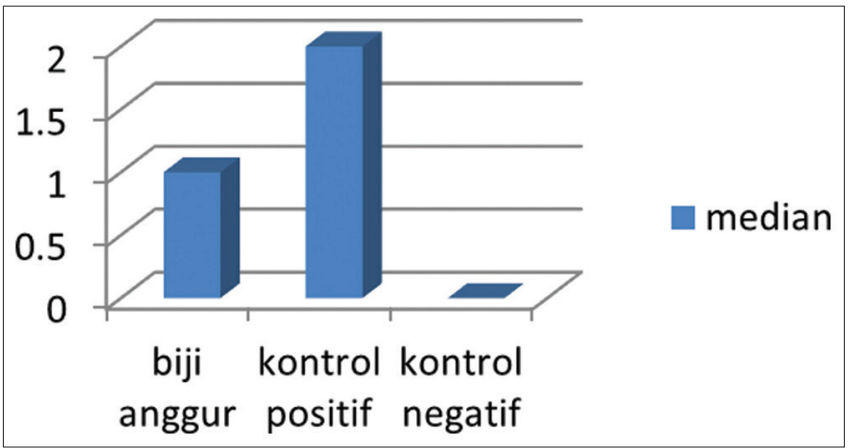

Chart 1: Median of each group reduce enzymatic degradation, which is important for enhancing hybrid layer stability and endurance of restoration adhesions [17]. Collagen crosslinker is an agent that forms inter- and intra-molecular crosslinks with type 1 collagen in dentine and helps stabilize the matrix [18].

The process of bonding to dentine occurs through a micromechanical mechanism by forming a hybrid layer. Bonding occurs by impregnating the dentine substrate through a mixture of resin monomers, to obtain a homogen hybrid layer that is highly dependent on the stability of the interfacial resin-dentine bond. At the same time, the hybrid layer is very important for dentine bonding, which is also the weakest and most vulnerable component of the resin-dentine surface [14]

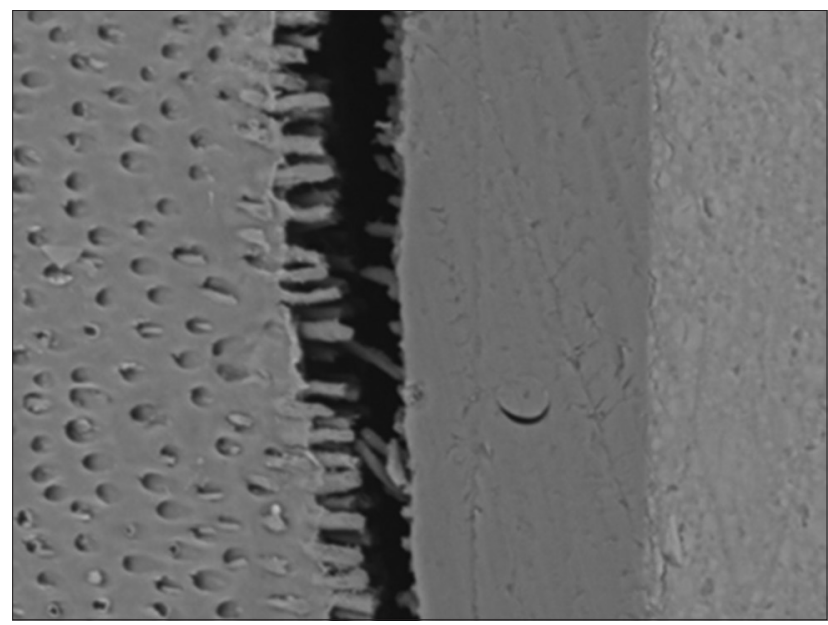

Fig. 1: Group of grape seed extract

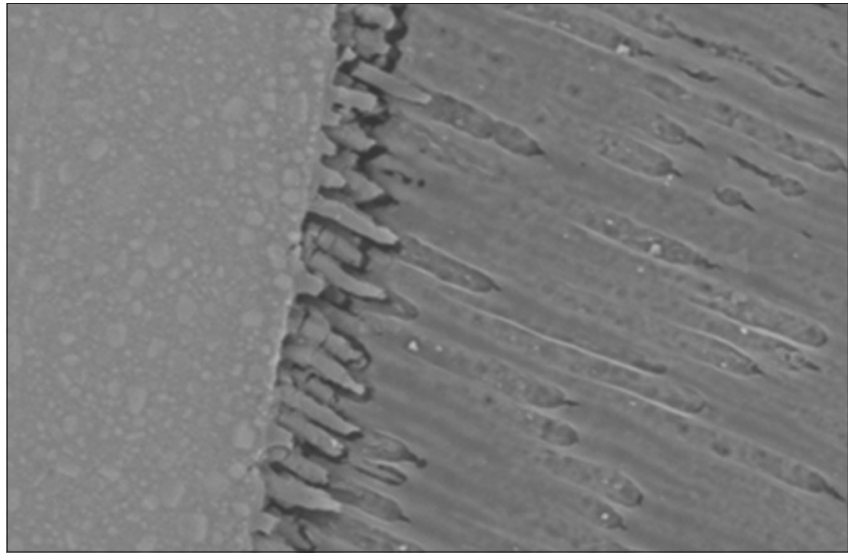

Fig. 2: Group of chlorhexidine

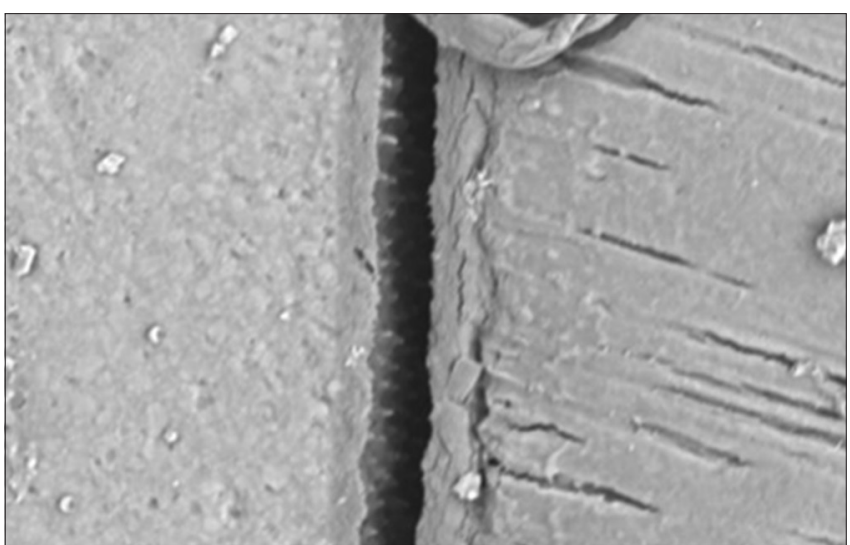

Fig. 3: Group of negative control 
Proanthocyanidine shows significant results in the strength of the bond in deep dentin [3]. This can be attributed to the specificity of proanthocyanidine to facilitate the proline hydroxylase enzyme, which catalyzes proline hydroxylation, which is a step in collagen biosynthesis.

In collagen fibrils through exogenous crosslinker agents, not only can they increase the modulus of elasticity of the collagen matrix and its efficacy but it can also ensure long-term stability of the hybrid layer by increasing the resistance of the collagen matrix. The use of crosslinker agents in the study can increase resistance to collagenase through the closure of open parts of the collagen matrix [Fig. 1]. In addition, crosslinkers have the ability to inhibit collagen molecules from gliding past each other under mechanical pressure [19].

Proanthocyanidine or condensed tannins consist of thick flavon-3-ol subunits, catechins, epicatechin, and epicatechin-3-0-gallate and are bound through C4-C8. This component is responsible for biological properties such as free radical cleansing and antioxidant activity. Proanthocyanidine contains several electron donor sites (hydroxyl sites) which allow binding of unstable molecules or free radicals by donating hydrogen atoms.

Proanthocyanidin consists of a high hydroxylation structure that is capable of forming non-soluble complexes with carbohydrates and proteins [17]. Proanthocyanidine and proteins interact in four ways: Covalent interactions, ionic interactions, hydrogen bond interactions, and hydrophobic interactions [3]. Crosslinker mechanism between proanthocyanidine and collagen mainly formed by hydrogen bonds between amine carbonyl proteins and phenolic hydroxyl groups in addition to covalent and hydrophobic bonds which are the main forces to stabilize collagen given proanthocyanidin and stabilize mechanical strength [20].

Proanthocyanidin can form hydrogen bonds by forming bridges with hydroxyl ions, carboxyl, amines, and collagen dentin amides [6]. The hydrogen bond between the phenolic hydroxyl group and the amide carbonyl group can increase the stability of collagen fibers and improve the mechanical properties of collagen [15]. In the process of forming hydrogen bonds, proanthocyanidin molecules can replace water molecules in the extrafibrillar collagen space [6].

$2 \%$ chlorhexidine showed the best inter crosslink between collagen fiber among all treatment groups. This is due to the inhibiting properties of MMP which can prevent the binding of metal ions, such as zinc and calcium to MMP, thus inhibiting its catalytic activity [Fig. 44].

Chlorhexidine can only electrostatically bind to demineralize dentine collagen, which slowly diffuses out of the collagen matrix through a competitive desorption mechanism in the presence of other cations. The interplay between chlorhexidine and the dentine matrix is based on the electrostatic force between the exhibited NH3 in the chlorhexidine molecule and $\mathrm{COOH}-$ or $\mathrm{OH}-$ in the negatively charged dentine. When applied in high concentrations, chlorhexidine can cause oversaturation of the binding part of the enzyme and remain bound to collagen fibrils for later release [21].

Application of $2 \%$ chlorhexidine for 1 minute to dentine, as a clinical protocol will produce rewetted collagen tissue and reduced degradation of resin-dentin bonds [21].

From results and discussion, the use of chlorhexidine $2 \%$ is better to form resin tags when compared with $6.5 \%$ grape seed extract and the negative control shows the lowest results in resin tag formation.

\section{CONCLUSION}

Grape seed extract can be considered to be used as an alternative crosslinker in composite resin restoration to maintain its adhesion to dentin.

\section{CONFLICTS OF INTEREST}

The authors declare that they have no known competing financial interests or personal relationships that could have appeared to influence the work reported in this paper.

\section{AUTHORS' CONTRIBUTION}

All authors conceived the original idea, designed the experiment, performed the experiment, and collected and analyzed data. All authors contributed to the interpretation of the results, wrote the manuscript, read and approved the final manuscript.

\section{REFERENCES}

1. Irawan B. Flowable characteristic of composite resin. J Dent Indones 2005;12:36-41.

2. Basri MH, Erlita I, Nahzi MY. Surface roughness of nanofilled composite resin after submersion in river and tap water. J Kedokt Gigi 2017;2:101-6

3. Srinivasulu S, Vidhya S, Sujatha M, Mahalaxmi S. Shear bond strength of composite to deep dentin after treatment with two different collagen crosslinking agents at varying time intervals. J Oper Dent 2012;37:485-91.

4. Puspitasari D. Difference of composite resin bond strength with one step and two steps self etch system. Dentino J Kedokt Gigi 2014;2:8994.

5. Castellan CS, Antunes A, Pereira NR. Effect of dentin biomodification using naturally derived collagen cross-linker: One-year bond strength study. Int J Dent 2013;2013:1-5.

6. Generosa DM, Suprastiwi E, Asrianti D. Effect of grape seed extract againts biodegradation of composite resin-dentin shear bond strength. J Phys 2017;884:1-6.

7. Heymann HO, Swift E, Ritter A. Sturdevant's Art and Science of Operative Dentistry. $6^{\text {th }}$ ed. Chicago: Mosby; 2011. p. 114-28.

8. Hass V, Martinez IV, Gutierrez MF, Moreira CG, Gotti VB, Feitosa P, et al. Collagen cross-linker on dentin bonding: Stability of the adhesive interfaces, degree of conversion of the adhesif, cytotoxicity and in situ MMP inhibition. Dent Mater 2016;32:732-41.

9. Green B, Yao X, Ganguly A. Grape seed proanthocyanidins increase collagen biodegradation resistance in the dentin/adhesive interface when included in an adhesive. J Dent 2010;38:908-15.

10. Dennis D, Abidin T. Degradation of resin-dentin bonds and current methods of its prevention. Indian J Restor Dent 2013;1:1-7.

11. Mangundjaja S, Nisa RK, Lasaryna S, Mutya FE. Engaruh Obat Kumur Khlorheksidin Terhadap Populasi Kuman Streptococcus mutans di Dalam air Liur. Indonesia, Denpasar: Perhimpunan Mikrobiologi; 2000. p. 1-9.

12. Srinivasulu S, Vidhya S, Sujatha M, Mahalaxmi S. Effect of collagen cross-linker on the shear bond strength of a self-etch adhesive system to deep dentin. J Conserv Dent 2013;16:135-8.

13. Aguiar TR, Vidal CM, Phansalkar RS, Todorova I, Napolitano JG, McAlpine JB, et al. Dentin biomodification potential depends on polypheol source. J Dent Res 2014;4:417-22.

14. Al-Ammar A, Drummond JL, Bedran-Russo AK. The use of collagen cross-linking agent to enhance dentin bond strength. J Biomed Mater Res B Appl Biomater 2009;91:419-24.

15. Ahmed HH, Salem AM, Mohamed MR, Shahat AA, Khalil WK, Mohamed SH. Experimental evidences for the promising therapeutic role of Vitis vinifera seed extract against nonalcoholic steatohepatitis. Int J Pharm Pharm Sci 2015;7:417-24.

16. Sayed DA, Fahmy SR, Soliman AM, Hussein NS. Antiulcerogenic efficacy of ethanolic extract of Vitis vinifera leaves in rats. Int J Pharm Pharm Sci 2016;8:163-72.

17. Epasinghe DJ, Yiu CK, Burrow MF, Tay FR, King NM. Effect of proanthocyanidin incorporation into dental adhesive resin on resindentine bond strength. J Dent 2012;40:173-80.

18. Khan SA, Khalid S, Rafique A, Khalid H. Effect of grape seed extract on shear bond strength at resin-dentin interface. Pak Oral Dent J 2017;37:152-7.

19. Balalaie A, Rezvani MB, Basir MM. Dual function of proanthocynidins as both MMP inhibitor and crosslinker in dentin biomodification: A literature review. Dent Mater J 2018;37:173-82.

20. Nagpal R, Singh P, Singh S, Tyagi SP. Proanthocyanidin: A natural dentin biomodifier in adhesive dentistry. J Res Dent 2016;4:1-6.

21. Sabatini C, Pashley DH. Mechanisms regulating the degradation of dentin matrices by endogenous dentin proteases and their role in dental adhesion. A review. J Dent 2015;27:203-14. 